\title{
ALGUNAS REFLEXIONES ACERCA DE LA TEORÍA DE LA MEMBRESÍA
}

Lucas S. Grosman*

\section{Introducción}

En "La autoridad del derecho y la injusticia económica y social”, Carlos Rosenkrantz se propone analizar si el derecho tiene autoridad incluso en condiciones de injusticia distributiva. Su respuesta es que sí la tiene, pero solamente respecto de aquellos súbditos del derecho que son miembros de la comunidad. La autoridad del derecho depende, para Rosenkrantz, del respeto al principio de membresía.

Algunas teorías tienen por objeto explicar una práctica o institución, esto es, entender los principios que la rigen y determinan su funcionamiento. Otras, en cambio, procuran analizar si una práctica o institución está justificada a la luz de un sistema de valores determinado, típicamente la moral. La teoría de la membresía pertenecería, de acuerdo al modo en que Rosenkrantz la presenta, a la primera categoría. En efecto, en la sección segunda, Rosenkrantz establece los requisitos que toda "explicación de una autoridad, para contar como tal cosa, debe satisfacer” (p. 18). Luego, en la sección tercera, procede a criticar teorías alternativas sobre esa base. Así, según Rosenkrantz, las teorías consensuales son inadecuadas porque no logran explicar "por qué todos aquellos a quienes el derecho se aplica deben someterse a él” (p. 23). Las teorías del Fair Play fallan porque "no pueden explicar la autoridad del derecho qua derecho" (p. 25). Rawls, por su parte, "no puede

* Tutor en Derecho y candidato a Doctor en la Ciencia del Derecho (J.S.D.), Yale Law School. 
explicar exitosamente por qué debemos acatar solo nuestro derecho" (p. 28). Las teorías epistémicas "no explican acabadamente que yo debo obedecer sólo mi derecho" (p. 31). Sobre la misma base, Rosenkrantz pondera los méritos de las teorías asociativas, ya que ellas, a diferencia de las anteriores, "garantizan una explicación de por qué aquellos que pertenecen a la comunidad, y sólo ellos, están alcanzados por la obligación de someterse al derecho" (p. 34). Sin embargo, la teoría de Dworkin, que pertenece a esta tradición, tampoco es totalmente adecuada, ya que ella "no explica todo lo que tenemos que explicar" (p. 38).

Como se puede advertir, la teoría la membresía sería, según Rosenkrantz, la mejor explicación de la autoridad del derecho. Su objetivo es reflejar el modo en que la autoridad del derecho funciona, y no analizar si tal funcionamiento está justificado a la luz de valores determinados. En consecuencia, el interrogante que Rosenkrantz pretende responder no puede ser interpretado en un sentido valorativo (¿debería aplicarse el derecho aún en situaciones de injusticia socioeconómica?) sino descriptivo de una práctica (¿se aplica el derecho aun en tales circunstancias?). Sin embargo, no se trata de una práctica concreta, como por ejemplo el derecho de tal o cual país en tal o cual momento histórico, sino de una práctica general o, en todo caso, del modo en que entendemos esa práctica general. En este sentido, la indagación de Rosenkrantz es conceptual; ella se refiere al concepto de la autoridad del derecho.

En la siguiente sección argumentaré que el principio de membresía no puede cumplir la función explicativa o conceptual que Rosenkrantz le asigna, ya que no logra capturar aspectos centrales de la práctica en cuestión y, de hecho, se da de bruces con los requisitos que el propio Rosenkrantz se impone. En la sección tercera me concentraré en los argumentos a los que Rosenkrantz recurre para justificar la aplicación del derecho en circunstancias de injusticia socioeconómica. 


\section{Un enfoque conceptual}

\section{Membresía y autosuficiencia}

Una de las primeras cosas que Rosenkrantz dice es que cualquier teoría acerca de la autoridad del derecho debe explicar "la obligación de obedecer el derecho simplemente porque es el derecho" (p. 17, con cita de Soper). Ahora bien, para cumplir este requisito, deberíamos renunciar a toda referencia al contenido o modo de creación de las normas jurídicas. En efecto, si obedecemos el derecho en virtud de la bondad intrínseca de sus normas o de su procedimiento de creación, no estamos obedeciéndolo porque es el derecho, sino porque es cierto tipo de derecho (por ejemplo, un derecho cuyas normas son liberales y su procedimiento de creación es democrático). En este sentido, y siguiendo un paralelismo que Rosenkrantz utiliza recurrentemente en este artículo, obedecer a los padres simplemente porque son los padres implica que se los debe obedecer más allá de que sus órdenes sean sabias, acertadas o prudentes (contenido), o hayan sido impartidas tras consultar al interesado o a sus abuelos (procedimiento de creación). Si un padre tuviera que justificar ante su hijo por qué éste debe hacerle caso, su respuesta, siguiendo a Rosenkrantz, debería ser, simplemente, "porque soy tu padre". Llamaré a este requisito "autosuficiencia".

Como dije, Rosenkrantz sostiene que toda teoría sobre la autoridad del derecho debe explicar su autosuficiencia, pues si no la teoría no es plausible. No es nada obvio, sin embargo, que la teoría que el propio Rosenkrantz desarrolla en su artículo logre explicar la autosuficiencia, según veremos a continuación.

Según el principio de membresía, una persona es miembro de la comunidad, y por ende el derecho tiene autoridad sobre ella, cuando (a) sus opiniones o intereses son de hecho tenidos en cuenta en la toma de decisiones; y (b) las normas de la comunidad no impiden que sus opiniones o intereses 
sean tenidos en cuenta en tal proceso. ${ }^{1}$ El problema es que este principio parece ser incompatible con el requisito de autosuficiencia. El principio de membresía implica que sólo en ciertas circunstancias el derecho tiene autoridad. El requisito de autosuficiencia simplemente no admite tales consideraciones o salvedades: si es derecho, debe ser obedecido y punto; ninguna condición de fondo o forma tiene cabida bajo este requisito.

\footnotetext{
${ }^{1}$ Estoy tratando de simplificar el complejo panorama que Rosenkrantz nos ofrece. En el capítulo V, Rosenkrantz afirma que los judíos en la Alemania nazi, los negros durante el apartheid, etc., no estaban obligados por el derecho. Según él, esto se debe en algunos casos a que los intereses de estas personas no contaban, y en otros a que no podían participar en la toma de decisiones (p. 42). Luego aclara que "para contar como un miembro de la comunidad debemos tener la posibilidad de ser tanto partícipes ('makers') como beneficiarios ('matter') de las decisiones colectivas" (p. 42). Y agrega: “debemos contar dos veces”. Pero luego califica esta conclusión de la siguiente manera: "El criterio de membresía no puede consistir en una exigencia directa e incondicionada de requisitos procedimentales y sustantivos". Según él, hacen falta ciertos “dobleces", y la definición de membresía que él sugiere, según yo la entiendo, es la siguiente:

No soy miembro si: (a) las instituciones de la comunidad no permiten que de hecho mis opiniones ni mis intereses cuenten; o (b) las instituciones están organizadas "a los efectos de que o mis opiniones o mis intereses no cuenten en dicho proceso" (p. 43).
}

Es decir que:

1. Basta con que una de las dos condiciones ( $a$ o b) se cumpla para que no haya membresía.

2. La primera condición (a) parece apuntar a los efectos (la cuestión de hecho) y la segunda (b) a la estructura de las instituciones ("están organizadas").

3. Para que la primera condición se cumpla, ni mis intereses ni mis opiniones deben contar en los hechos. Es decir que si una de las dos cosas cuenta (intereses u opiniones), esta condición no se cumple.

4. Sin embargo, para que la segunda condición se cumpla, alcanza con que "o mis opiniones o mis intereses no cuenten". Es decir que en este caso, a diferencia del anterior, basta que una de las dos cosas no cuente para que la condición se cumpla. Hay una asimetría entre ambas condiciones.

Esto nos deja con el siguiente cuadro. No soy miembro si: (i) las instituciones, como cuestión de hecho, no permiten que mis opiniones ni mis intereses cuenten; o si (ii) más allá de lo anterior, las instituciones están organizadas para que mis opiniones o mis intereses no cuenten. Si lo ponemos en positivo, soy miembro si: (i) las instituciones, como cuestión de hecho, permiten que mis opiniones o mis intereses cuenten; y, además, (ii) las instituciones están organizadas para que mis opiniones y mis intereses puedan contar.

Más adelante Rosenkrantz no habla de opiniones e intereses, sino de participación e intereses (p. 44). Sin embargo, una cosa es poder participar y otra que mis opiniones sean tenidas en 
Volvamos a la analogía favorita de Rosenkrantz, esto es, la autoridad paterna. El requisito de autosuficiencia implica, como dije, que los padres deben ser obedecidos por sus hijos sencillamente porque son sus padres. Supongamos que en el caso de la relación entre padres e hijos, el sucedáneo del requisito de membresía es que las opiniones y los intereses de los hijos deben ser tenidos en cuenta por sus padres al tomar decisiones que los conciernen. Esto quiere decir que cuando las decisiones de los padres no respetan el principio de membresía, ellas carecen de autoridad. Pero, en tal caso, la frase "debés obedecerme sencillamente porque soy tu padre", que refleja la autosuficiencia, ha perdido todo sentido. No basta con ser padre para tener autoridad; hace falta, además, cumplir con el principio de membresía. Del mismo modo, Rosenkrantz afirma que los judíos no estaban obligados a obedecer el derecho en la Alemania nazi, al igual que los negros durante el apartheid, las mujeres cuando no gozaban de derecho a voto y los argentinos durante el Proceso. Nuevamente, si el derecho tuviera que ser obedecido simplemente por ser tal, estas excepciones no podrían ser explicadas.

Tal vez Rosenkrantz tenga algo distinto en mente. Podría pensarse que, para él, las condiciones de fondo y forma que informan el requisito de membresía no constituyen rasgos intrínsecos del derecho en sí sino circunstancias externas a él. Es decir, la membresía no dependería del tipo de derecho sino del tipo de comunidad. El derecho -cualquier derecho, todo derecho- debería obedecerse siempre y cuando se cumplan ciertas condiciones en la comunidad en cuestión; se debe obedecer "simplemente porque es derecho", pero sólo cuando la comunidad respeta el principio de membresía.

No obstante, para que esta distinción sea sostenible, la calidad de miembro de la comunidad debe ser totalmente independiente del derecho. A poco de meditarlo, esto no resulta plausible. Es en buena medida como

cuenta. Lo segundo es más ambicioso. Tampoco resulta claro si Rosenkrantz utiliza como sinónimos 'el modo en que las instituciones están organizadas' y 'las normas'. Entiendo que sí. En cualquier caso, creo que sería útil que Rosenkrantz aclarara este panorama. 
consecuencia del contenido y modo de sanción de las normas jurídicas que los judíos en la Alemania nazi o los negros durante el régimen de Jim Crow son arquetipos de alienación, es decir, de ausencia de membresía. Más aún, este rasgo no constituye una peculiaridad de los ejemplos elegidos por Rosenkrantz, sino un elemento esencial en toda relación entre la comunidad y sus integrantes. El derecho es la principal herramienta con que cuenta la comunidad para integrar o excluir a los individuos. Es inevitable, por lo tanto, que la calidad de miembro deba ser analizada en gran medida en función de las normas jurídicas. Si la noción de membresía no puede escindirse del contenido y el modo de creación del derecho, la distinción entre los rasgos intrínsecos del derecho y las circunstancias que lo rodean no sirve para tornar compatibles el principio de membresía y el requisito de autosuficiencia.

\section{Membresía y generalidad}

También el requisito de generalidad presenta dificultades para el principio de membresía. El requisito de generalidad, recordemos, implica según Rosenkrantz que las teorías sobre la autoridad del derecho deben explicar por qué todos los súbditos del derecho, y no sólo algunos, deben obedecerlo. Más aún, Rosenkrantz considera que el requisito de generalidad funciona, precisamente, como un requisito, es decir una condición que se debe satisfacer plenamente, y no como un principio u objetivo al que se debe tender. En otras palabras, Rosenkrantz no dice que las teorías sobre la autoridad deben tratar de ser lo más generales posibles, sino, sencillamente, que deben ser generales. Alguien tiene autoridad como padre, enfatiza, "si tiene autoridad sobre todos sus hijos" (p. 18).

Invocando el requisito de generalidad, Rosenkrantz critica las teorías que justifican el deber de obedecer el derecho sobre la base del consentimiento o los beneficios recíprocos. Estas teorías, dice, no logran explicar por qué todos deben obedecer el derecho, y no solamente los que lo consintieron o se benefician con él. Pero cabe preguntarse si el principio de membresía es 
realmente inmune a igual reproche. Al fin y al cabo, este principio implica que sólo quienes son miembros de la comunidad deben obedecer el derecho. No todos deben obedecer el derecho, como el requisito de generalidad demanda, sino sólo algunos: los miembros.

Ello no obstante, podría alegar Rosenkrantz, la teoría de la membresía es superadora de las teorías basadas en el consentimiento o el fair play, ya que la primera es más general que estas últimas: son más las personas que no consienten el derecho o que no se benefician con él que aquellas que no satisfacen el principio de membresía. Es decir que la teoría de la membresía es, al menos, más general que sus competidoras. Esta respuesta, sin embargo, no sería satisfactoria. En primer lugar, que el número de miembros de la comunidad sea mayor que el de personas que consienten el derecho o se benefician con él es una cuestión coyuntural y controvertible, no un rasgo inherente a todas las comunidades. La teoría de Rosenkrantz pretende iluminar cuestiones conceptuales acerca de la autoridad, y sólo lo logrará en la medida en que se mantenga al margen de especulaciones coyunturales. En segundo lugar, como vimos, la generalidad es una condición que debe satisfacerse plenamente, un requisito, no un principio u objetivo al que se debe tender. No basta, por ende, que la teoría de la membresía sea más general que otras.

\section{El concepto subyacente de derecho}

El requisito de autosuficiencia exige que toda teoría sobre la autoridad del derecho explique la obligación de obedecer el derecho sólo porque es el derecho, es decir, con independencia de consideraciones que califiquen su contenido o modo de creación. El requisito de generalidad, por su parte, exige que se explique por qué todas las personas sujetas al derecho, y no sólo algunas, deben obedecerlo. El principio de membresía desafía al requisito de autosuficiencia al establecer que una persona A no tiene el deber de obedecer el derecho X, a pesar de que es el derecho, si el derecho X no la trata como miembro (o, si se quiere, si el derecho $\mathrm{X}$ es el derecho de una comunidad 
que no trata a A como miembro; como dije antes, no creo que esto cambie las cosas). El principio de membresía desafía, asimismo, al requisito de generalidad, ya que por más que A esté sometido al derecho $\mathrm{X}$, no debe obedecerlo si no es miembro.

¿Puede Rosenkrantz sortear estas dificultades? ¿Es posible reconciliar estos dos requisitos (que él se impone) con su principio de membresía? La respuesta debe buscarse en el concepto de derecho que subyace a la teoría de Rosenkrantz. Para evitar las contradicciones descriptas, Rosenkrantz requiere una concepción del derecho en virtud de la cual el principio de membresía no sea algo que algunos derechos satisfacen y otros no sino un elemento constitutivo de todo derecho. Así, la membresía debe ser parte del concepto de derecho, y no un rasgo coyuntural de algunos derechos. El derecho no es derecho si no cumple el principio de membresía, o, en todo caso, el derecho sólo es derecho respecto de los miembros.

Esta concepción del derecho nos permitiría entender por qué Rosenkrantz parece creer que su teoría de la membresía es compatible con el requisito de autosuficiencia. La idea es que sólo es apropiado considerar que una norma es derecho respecto de una persona A si la comunidad política que dicta esa norma trata a A como miembro. Cuando A no es tratado como miembro, su eventual desobediencia a una norma que la comunidad pretende aplicarle no debería ser interpretada como una desobediencia al derecho, ya que, más allá de lo que el derecho positivo diga, esa norma no sería realmente derecho para A. En estas condiciones, explicar la autoridad del derecho sobre A a partir del principio de membresía no se opone al requisito de autosuficiencia, ya que si A es miembro debe obedecer el derecho por el solo hecho de que es derecho, pero si A no es miembro ese derecho no es derecho para A.

Sobre la base de este concepto de derecho, podríamos también reconciliar la teoría de Rosenkrantz con el requisito de generalidad. Si las normas emanadas de la autoridad política sólo son derecho si respetan el principio de membresía, entonces, en efecto, todas las personas sujetas al derecho deben obedecerlo. El derecho, podrá decir Rosenkrantz, tiene 
autoridad sobre todas ellas. Dado que el derecho nazi no era derecho para los judíos, el hecho de que, como dice Rosenkrantz, éstos no tuvieran el deber de obedecerlo no contraría el requisito de generalidad.

En resumen, el requisito de generalidad y el de autosuficiencia sólo pueden resultar compatibles con el principio de membresía si entendemos que la membresía es un elemento constitutivo del concepto de derecho. El problema es que el análisis conceptual no consiste en estipular significados; Rosenkrantz no podría presuponer sin más que "derecho" es algo que implica membresía. Para que tal concepción sirva en efecto como base de sustento para su análisis, ella debe reflejar prácticas sociales concretas, típicamente el modo en que los actores del derecho (en especial jueces, abogados y juristas) lo entienden, se refieren a él y lo utilizan en sus razonamientos. Hart, por ejemplo, se apoya en este tipo de elementos para argumentar que existe un aspecto interno que distingue a las normas jurídicas de las órdenes respaldadas por una amenaza, criticando así la posición defendida por Austin. ${ }^{2}$ Dworkin, por su parte, ataca la tradición positivista en la que Hart se enrola sobre la base de que ésta no logra reflejar ciertas prácticas concretas propias de la administración de justicia, específicamente la invocación de principios de corte moral como fundamento de las decisiones. ${ }^{3}$ No importa si estos argumentos logran refutar las teorías que atacan; las diferencias entre Hart y Dworkin son, de hecho, algunas de las cuestiones más disputadas en la filosofía del derecho de las últimas décadas y, por cierto, no pretendo interceder en ese debate. Traigo estos argumentos a colación sólo para ilustrar la estructura del análisis conceptual: éste se asienta en prácticas sociales para iluminar el uso de un concepto. No hay nada similar en el enfoque de Rosenkrantz. Nada, al menos, que justifique incluir el principio de membresía en el concepto de derecho.

${ }^{2}$ H. L. A. Hart, The Concept of Law, $2^{\text {nd }}$ Edition (Oxford: Clarendon Press, 1994).

${ }^{3}$ Ronald Dworkin, Taking Rights Seriously (Cambridge, Massachussets: Harvard University Press, 1977). 
Esto, en abstracto, no tendría por qué ser un problema, ya que al fin y al cabo una teoría sobre la autoridad del derecho no tiene por qué incursionar en un análisis sobre el concepto del derecho: podría, sencillamente, presuponer un concepto de derecho, en la medida en que tal concepto fuera generalmente aceptado u obviamente razonable. Lo que ocurre es que Rosenkrantz ha optado por criticar teorías rivales sobre la base de una serie de requisitos conceptuales que sólo resultarían compatibles con su propia teoría si se presupusiera una concepción del derecho que, lejos de ser generalmente aceptada, resulta bastante peculiar. La membresía, en efecto, no es algo que en general entendamos como constitutivo del concepto de derecho. De hecho, creo que existen buenas razones para rechazar una concepción del derecho que se asienta en la membresía, ya que ella no logra capturar aspectos centrales del derecho, como veremos a continuación.

4. Los deberes de quienes no son miembros

Si tomamos la definición de membresía de Rosenkrantz, ¿los extranjeros son miembros de la comunidad? Rosenkrantz plantea que, para que una persona sea miembro de la comunidad, (a) sus opiniones o intereses deben ser de hecho tenidos en cuenta en la toma de decisiones y (b) las normas de la comunidad no deben impedir que sus opiniones o intereses sean tenidos en cuenta en tal proceso. ${ }^{4} \mathrm{El}$ problema es que los extranjeros ni siquiera gozan, en general, de derecho a voto, con lo cual no se cumple respecto de ellos por lo menos la segunda condición. Para que una persona que no tiene derecho a voto de todas formas sea considerada miembro de la comunidad, debemos exigir, al menos, que tal restricción se justifique en virtud de genuinas razones paternalistas, como ocurre, por ejemplo, en el caso de los menores de 18 años y los dementes ${ }^{5}$. Dado que en el caso de los extranjeros no existen tales

\footnotetext{
${ }^{4}$ Es decir que, desde el punto de vista de las normas (o la organización de las instituciones), debe ser posible que tanto las opiniones como los intereses cuenten. Ver nota 1.

${ }^{5}$ Código Electoral Nacional, art.1, 3 inc. a y b.
} 
razones u otras análogas, no corresponde contarlos como miembros de la comunidad si seguimos la definición de Rosenkrantz. No cabe duda, sin embargo, de que esta circunstancia por sí sola no los exime de la obligación de obedecer el derecho. Un caso más extremo es el del turista. Nadie podría alegar seriamente que el turista es miembro de la comunidad, pero, nuevamente, eso no basta para considerar que no está obligado a obedecer el derecho del lugar donde se encuentra.

Creo, dicho sea de paso, que las teorías del consentimiento no logran brindar una explicación complementaria en estos casos. Es verdad que el inmigrante o el turista, a diferencia del nativo, en algún sentido relevante consiente que se le apliquen las normas del país que visita, pero piénsese en el siguiente caso. Una persona es secuestrada en un país y luego trasladada subrepticiamente a un país vecino. En un momento de descuido de sus captores, logra escaparse. Se encuentra entonces en un país al que no eligió entrar. La teoría del consentimiento ni remotamente alcanzaría este caso; ello no obstante, resulta claro que esta persona no puede pretenderse al margen de las normas del país en el que involuntariamente se encuentra, con escasas excepciones.

Existen muchos otros casos similares. Además de los menores, los dementes y los sordomudos, no tienen derecho a voto en Argentina los condenados por delitos dolosos a pena privativa de la libertad por el tiempo de la condena ${ }^{6}$, ni los condenados por violaciones a las leyes de juegos prohibidos por tres años ${ }^{7}$, ni los desertores ${ }^{8}$, ni los declarados rebeldes en causa penal ${ }^{9}$. Nuevamente, parece claro que estas personas no son miembros de la comunidad a la Rosenkrantz. Como dije, solamente sólidas consideraciones paternalistas podrían justificar que, a pesar de tal privación

\footnotetext{
${ }^{6}$ Código Electoral Nacional, art. 3 inc. e.

${ }^{7}$ Código Electoral Nacional, art. 3 inc. f.

${ }^{8}$ Código Electoral Nacional, art. 3 inc. g.

${ }^{9}$ Código Electoral Nacional, art. 3 inc. i.
} 
del derecho a votar, consideremos a estas personas miembros de la comunidad en el sentido que Rosenkrantz atribuye al término. No veo que tales consideraciones se encuentren presentes y, por ende, debemos concluir que estos casos no logran pasar el test de membresía que Rosenkrantz nos propone. A pesar de ello, nuevamente, el derecho los alcanza.

Rosenkrantz podría alegar que estos son casos aislados que no logran llegar a la médula de su teoría. Creo, por el contrario, que estos casos revelan un problema estructural. El derecho en general no impone deberes a partir de la relación entre la comunidad y el individuo, sino que regula las acciones concretas que el individuo realiza. Es decir que el punto de contacto relevante entre el individuo y las normas jurídicas son sus actos, no su status dentro de la comunidad. Más aún, el derecho de un estado en principio sólo alcanza los actos de un individuo cuando ellos se realizan en el territorio de ese estado o tienen efectos en él, independientemente de que quienes los realicen sean ciudadanos, residentes o turistas. De hecho, ni siquiera hace falta que la persona pertenezca a alguna de esas categorías para que las normas jurídicas alcancen sus acciones. Pensemos en el alcance del derecho argentino. Si un uruguayo, desde la margen oriental del Río de la Plata, lanza un misil contra la Ciudad de Buenos Aires, el derecho argentino sin duda alcanzará tal acción; lo mismo ocurrirá si un francés, sin pisar nuestro suelo, organiza el ingreso de drogas ilegales en Argentina, o si una empresa alemana se fusiona con una inglesa y esto tiene efectos en nuestro territorio. En todos estos casos, el punto de contacto relevante es el lugar donde el acto produce efectos, no dónde fue realizado ni, mucho menos, el status del agente dentro de nuestra comunidad.

Tal vez se piense que en estos casos el aspecto distintivo es que las conductas generan efectos trascendentes, penales o cuasi penales. Nada de eso es necesario. Si yo firmo un vulgar contrato comercial con un japonés y sus efectos tienen lugar en Argentina, numerosas normas del derecho argentino alcanzarán a mi contraparte aunque jamás haya abandonado su país. Incluso las normas tributarias tienden a funcionar de esta manera: un extranjero que pretenda importar mercaderías deberá pagar aranceles en el país de destino, 
y quien posee bienes en un país donde no reside debe hacerse cargo de los impuestos que los gravan. La conclusión es bastante sencilla: las normas jurídicas de un país, en general, alcanzan los actos realizados o con efectos en la jurisdicción territorial del país en cuestión, sin importar el particular status del agente en la comunidad. Una concepción del derecho asentada en la membresía pasa por alto este aspecto central.

Se trata, por supuesto, de un principio general, no absoluto. Existen excepciones, algunas de ellas de interés. El artículo 21 de la Constitución argentina, por ejemplo, establece: "Todo ciudadano argentino está obligado a armarse en defensa de la patria y la Constitución, conforme las leyes que al efecto dicte el Congreso y a los decretos del Ejecutivo nacional. Los ciudadanos por naturalización son libres de prestar o no este servicio por el término de diez años contados desde el día en que obtengan su carta de ciudadanía." Aquí sí, claro está, el status dentro de la comunidad es relevante, pero convengamos que se trata de una obligación muy especial. De lo que se trata es nada menos que de dar la vida por la patria. Esto es sin duda lo máximo que la comunidad política puede exigir al individuo, y no debe sorprendernos que tal deber esté reservado para quienes, a su vez, gozan de plenos derechos políticos. Tal vez la teoría de la membresía ilumine esta peculiar obligación. Esto no sería trivial, ya que sin duda se trata de una obligación que merece análisis, pero mucho distaría de explicar la autoridad del derecho en general.

El presente análisis nos obliga a descartar, asimismo, el requisito de particularidad que Rosenkrantz esgrime contra Rawls, Raz y Nino. Para Rosenkrantz, este requisito implica que una teoría sobre la autoridad del derecho debe explicar por qué una persona debe obedecer su derecho y no el de otras comunidades. Como vimos, esto no es así: una persona no sólo debe obedecer el derecho de la comunidad de la que es miembro; debe obedecer el derecho de toda comunidad en la que sus actos produzcan efectos que tal comunidad juzga relevantes jurídicamente, lo que la lleva a estar sujeta a normas de comunidades a las que no sólo no pertenece sino que ni 
siquiera ha visitado. No puede decirse, en consecuencia, que uno deba obedecer sólo "su" derecho, como el requisito de particularidad presupone.

En resumen, ni el requisito de autosuficiencia ni el de generalidad son compatibles con el principio de membresía a menos que adoptemos una particular concepción del derecho que, primero, Rosenkrantz no hace explícita ni defiende, y, segundo, no parece plausible. Por su parte, el principio de membresía satisface, sí, el requisito de particularidad, pero este requisito carece de valor conceptual, ya que sencillamente no logra capturar aspectos centrales de la práctica de aplicar el derecho.

Rosenkrantz, en definitiva, no puede aferrarse a un enfoque conceptual para defender su principio de membresía. El derecho no toma la membresía como punto de referencia sino que, en esencia, atiende a los efectos de las conductas sobre la comunidad, en especial, pero no solamente, cuando esas conductas tienen lugar en el territorio del estado. En este sentido, las dificultades de la teoría de Carlos Rosenkrantz no se refieren al particular contenido del principio de membresía, sino al modo en que éste concibe el punto de contacto entre las normas jurídicas y los actos alcanzados por ellas.

Ahora bien, Rosenkrantz podría argumentar que si bien la aplicación del derecho tal como la conocemos no tiende a reflejar el principio de membresía, esto puede significar simplemente que tal práctica es indefendible desde el punto de vista valorativo. Rosenkrantz podría ir incluso más lejos y afirmar que la aplicación del derecho de un estado a, por ejemplo, los turistas, es inmoral. Esto implicaría cambiar radicalmente el plano de análisis: ya no estaría en juego la explicación de la autoridad, sino su justificación. Rosenkrantz, como vimos, ha optado por encarar la cuestión de otra manera. Pero ello no nos debería llevar a desdeñar argumentos valorativos. Al fin y al cabo, creo que es en el campo de la justificación donde se debe librar la batalla relevante. La pregunta central es si está justificado aplicar el derecho aun en circunstancias de injusticia económica, más allá de que ello sea compatible o no con el concepto de autoridad. Creo que, a pesar del tono explicativo de su análisis, Rosenkrantz tiene una teoría justificatoria, ya que 
su defensa del principio de membresía no carece de argumentos de esa índole. En la siguiente sección encararé el análisis de esos argumentos. Confío en que el análisis conceptual que nos entretuvo en esta sección servirá para encarar tal tarea con mayor claridad.

\section{La justificación de la autoridad del derecho}

\section{El deber moral de obedecer el derecho}

Si entendemos el principio de membresía como un principio moral, sólo quien es tratado como miembro tiene el deber moral de obedecer el derecho. Tal principio no resulta atractivo. Para empezar, mi obligación moral de obedecer el derecho no puede depender únicamente de cómo se me trata a mí. Ella debe depender, también, de cómo trata el derecho a las otras personas cuyos intereses se ven afectados por mi cumplimiento o incumplimiento de sus normas. Muchas normas jurídicas, al fin y al cabo, no regulan solamente mi relación con el estado sino que conciernen mi relación con terceros. ${ }^{10}$ Pensemos en algunas situaciones propias de las sociedades que Rosenkrantz usa como ejemplo. ¿Tenían los ciudadanos alemanes no judíos el deber moral de obedecer normas antisemitas que regulaban sus relaciones con los judíos? Por ejemplo, ¿debían obedecer las normas que prohibían comprar en negocios cuyos dueños eran judíos? ¿Debían cumplir las normas que mandaban delatar a los judíos que pretendían huir de la deportación a campos de concentración, como así también a quienes los estuvieran ocultando en sus casas? Pasando a otro continente, ¿debían los blancos del Sur de Estados

\footnotetext{
${ }^{10}$ Como señala Kelsen en su Teoría General del Derecho y el Estado, también estas normas que regulan relaciones entre particulares imponen deberes a los funcionarios estatales, y en ese sentido atañen en esencia a la relación entre el particular y el estado. Esto, sin embargo, no priva de utilidad conceptual ni de relevancia moral a la distinción señalada.
} 
Unidos acatar las normas que les prohibían casarse con negros, o la infinidad de regulaciones que plasmaban el slogan "separados pero iguales" del régimen Jim Crow? La obvia respuesta, en todos estos casos, es "no", pero ello no se debe a que las personas alcanzadas por las normas en cuestión no fueran miembros de la comunidad, ya que, si nos atenemos a la definición de Rosenkrantz, sí lo eran. La razón por la que creemos que los alemanes no judíos o los blancos en el Sur de Estados Unidos no debían acatar normas racistas es independiente de su calidad de miembros. Sencillamente, creemos que esas normas jurídicas eran contrarias a normas morales básicas. Lo interesante es que esa notoria inmoralidad es la misma razón que nos lleva a afirmar que los judíos o los negros no tenían la obligación moral de obedecer las normas que les prohibían salir del ghetto en el primer caso o usar baños públicos destinados a blancos en el segundo. De hecho, si tomamos una norma como la que prohibía los casamientos entre blancos y negros, resulta claro que ni unos ni otros tenían el deber moral de obedecerla, a pesar de que los primeros eran miembros y los segundos no. ${ }^{11}$

El principio de membresía implica que quien no es miembro no debe cumplir ninguna norma y quien es miembro debe cumplirlas todas. Los ejemplos anteriores muestran que en algunos casos los miembros no tienen obligación de obedecer una norma; los ejemplos que siguen muestran que, en otros casos, quienes no son miembros sí tienen tal obligación. Pensemos nuevamente en algunos de los casos que Rosenkrantz plantea como arquetipos de la alienación: las mujeres sin voto o los argentinos durante la dictadura. No creo, a diferencia de Rosenkrantz, que estos casos de exclusión impliquen la ausencia de todo deber de obedecer el derecho. No diría, por ejemplo, que los argentinos simplemente no debían obedecer el derecho entre 1976 y

\footnotetext{
${ }^{11}$ Sería posible alegar que en las sociedades como las descriptas nos hallamos frente a un grado de segregación tal que es difícil hablar de comunidad o de membresía. Pero creo que es innegable que si la categoría "miembro" tiene algún contenido, debe alcanzar a los blancos del régimen Jim Crow o a los no judíos en la Alemania nazi. Negar esto trivializaría la noción de membresía al punto de volverla irreconocible.
} 
1983. Creo que, obviamente, ciertas normas jurídicas no debían ser obedecidas, pero el tipo de generalización que el principio de membresía implica parece inaceptable. Al fin y al cabo, muchas de las normas vigentes durante ese período regulaban relaciones entre particulares. Pensemos, por ejemplo, en normas del Código Civil relativas a la responsabilidad civil contractual y extracontractual. ¿No existía ninguna obligación moral de obedecerlas? O pensemos, si no, en las normas del Código Penal: ¿estuvimos los argentinos moralmente al margen de ellas durante la dictadura? No lo creo.

Podría pensarse que en estos casos los deberes de obedecer estas normas legales dependen en realidad de que ellas tienden a coincidir con normas morales, y que son éstas, no las normas legales, la fuente del deber de obediencia. Sin duda algo de eso hay, pero creo que la cuestión es más compleja. La moral no regula la infinidad de aspectos que las normas legales alcanzan. Puede existir un deber moral de obedecer normas legales aun en casos en que la moral es neutral acerca de su contenido. Por ejemplo, la moral es neutral acerca de si los autos deben circular por al derecha o la izquierda, pero eso no implica que sea neutral acerca de si se debe cumplir la norma que, por las razones que fueran, impone la circulación por la derecha. El cumplimiento de esta norma puede ser un deber moral, a pesar de que nada dispone la moral, en abstracto, sobre la cuestión de fondo.

La existencia de un deber moral en esos casos depende, al igual que el principio de membresía, de consideraciones de fondo y forma. Las consideraciones de forma se vinculan con el procedimiento de creación de la obligación legal; las de fondo, con su contenido. Ambos tipos de consideraciones interactúan; la debilidad de unas puede verse compensada por la fortaleza de las otras. Por eso, en ocasiones puede existir un deber moral de cumplir una norma debido a consideraciones de forma, aunque el contenido de tal norma difiera de lo que la moral dispone al respecto. En tal sentido, si el procedimiento de creación de las normas jurídicas reúne ciertas características de pedigree democrático, probablemente existirá un deber moral de obedecerlas incluso si alguna de ellas se aparta de lo que la moral ideal 
diría acerca de la cuestión de fondo. Digo "probablemente", sin embargo, porque esto será así sólo dentro de ciertos límites. Si la norma en cuestión no sólo se aparta de lo prescripto por la moral ideal sino que viola un principio básico de ésta, no existirá un deber moral de obedecerla por más cristalino que haya sido su mecanismo de creación. Se podrá decir, con razón, que este último supuesto es improbable, en especial si partimos de una noción robusta de la democracia que la distinga de la mera regla de la mayoría. La distinción, no obstante, es conceptualmente importante.

Esta dinámica es mucho más compleja de lo que el principio de membresía, en tanto principio moral, puede reflejar. La dificultad fundamental es que el principio de membresía se refiere a tipos de personas, de forma tal que si una persona es miembro, tiene el deber de obedecer todas las normas emanadas de la comunidad política a la que pertenece, $y$, si no es miembro, no tiene obligación alguna. Existen distinciones moralmente relevantes que invalidan este tipo de clasificación blanquinegra. Como vimos, en ocasiones un miembro no tiene el deber moral de obedecer el derecho y en otras quien no es miembro sí lo tiene. Más aún, en uno y otro caso esto no depende de su calidad de miembro -ni siquiera de cuán miembro es- sino de otros factores vinculados con el contenido de la norma y su procedimiento de sanción. No existe, por ello, una fórmula lineal y fácil de aplicar para determinar si existe un deber moral de obedecer el derecho. Sólo un análisis caso por caso, persona por persona y norma por norma podrá darnos una respuesta.

No debe sorprendernos que Rosenkrantz rehúya un análisis tan pormenorizado y prefiera pintar con la brocha gorda del principio de membresía. La razón es clara: para Rosenkrantz, es importante construir autoridad, encontrar un principio que nos permita afirmar sin más, en un país como Argentina, que todos debemos obedecer el derecho, a pesar de las obvias injusticias que nos afectan. Rosenkrantz cree que el derecho es la mejor manera de superar tales injusticias y que por ende debemos apostar a su autoridad, reafirmarla, creer en ella y hacerla efectiva. Estoy de acuerdo. Sin embargo, no creo que tal empresa pueda servir para justificar un deber 
moral de obedecer el derecho en cabeza del individuo. Esto, como veremos a continuación, no priva al argumento de Rosenkrantz de peso justificatorio, pero nos obliga a ubicarlo en otro plano.

2. El deber de imponer el derecho

Rosenkrantz analiza la cuestión de la autoridad del derecho a partir de las razones que tiene el individuo para obedecerlo. Dentro de ese marco, apela al argumento del cambio sistémico; gracias al derecho, dice, la comunidad puede adoptar decisiones que permitan su progreso, tal vez incluso su supervivencia. Creo que tal justificación es importante, pero ella no puede servir como fundamento de un deber individual de obedecer el derecho. Existe una importante distinción entre el deber del individuo de obedecer el derecho y el deber del estado de imponerlo. El argumento del cambio sistémico, según argumentaré, pertenece a la segunda categoría.

Puede ser que yo no esté moralmente obligado a obedecer una norma pero que el estado esté moralmente facultado, incluso obligado, a imponérmela. Distintas consideraciones morales juegan en uno y otro caso. Por ejemplo, en la medida en que consideraciones relativas al bienestar general estén inscriptas en la moral que rige los actos del estado, éste deberá promover, en ocasiones, soluciones que perjudiquen a unos pocos para favorecer a muchos otros. No importa a los fines de esta discusión en qué circunstancias los números cuentan de esta manera, o, dicho de otra forma, en qué casos las consideraciones consecuencialistas desplazan a las deontológicas; basta aceptar como punto de partida que al menos en algunos casos los deberes morales del estado imponen que este tipo de consideraciones cuenten más de lo que contarían respecto de los deberes de los individuos. Supongamos que el gobierno debe decidir si adopta una medida económica que perjudica a 500 personas u otra que perjudica a 500.000 (entre las cuales no están incluidas las primeras 500). Y supongamos, para facilitar el ejemplo, que no hay 
diferencias relevantes entre los dos grupos de potenciales perjudicados, es decir, que los integrantes de ambos son igualmente ricos o pobres, jóvenes o viejos, sanos o enfermos, etc. Difícil es negar que en este caso el gobierno debe adoptar la decisión que perjudique al menor número de gente. Esta consideración, sin embargo, no tiene por qué contar a la hora de definir el deber moral de los integrantes del grupo de 500 personas. No diríamos que estas personas tienen el deber moral de promover la decisión que los perjudicaría, o, una vez adoptada, de no impugnarla ante los tribunales. Probablemente tengan el deber de acatarla, pero ese no es el punto que me interesa aquí: lo que quiero mostrar es que los deberes morales del estado no pueden reducirse a los de los ciudadanos, y viceversa.

Pensemos sino en los tan mentados casos de naufragios en los que el número de náufragos excede la capacidad del bote salvavidas y se debe decidir quién se baja, o sea, quién muere. En estas circunstancias, supongamos que la autoridad competente -el capitán- adopta una decisión que, en las circunstancias, resulta razonable, por ejemplo, dejarlo librado al azar. ${ }^{12}$ Aunque no diríamos que el náufrago desfavorecido por tal decisión tendrá el deber de acatarla (¿quién le reprocharía que luche por su vida con uñas y dientes?), esto no obsta a que la autoridad tenga el deber de ejecutar tal decisión. El deber de esta autoridad deriva de su obligación de velar por la seguridad de los pasajeros. Si el capitán optara por no ejecutar su decisión y dejara que todos murieran ahogados, no estaría honrando tal obligación. Esa consideración, insisto, es decisiva para poner en cabeza del capitán el deber de ejecutar su decisión, a pesar de que sería difícil encontrar un deber correlativo de obedecerla en cabeza de los náufragos desfavorecidos.

\footnotetext{
${ }^{12}$ El juez que presidió el juicio de United States v. Holmes, cuyos hechos se asemejan a los descriptos arriba, sostuvo que los pasajeros debían ser rescatados antes que la tripulación, excepto cuando ésta era esencial para la operación del bote, en cuyo caso la selección debía realizarse por sorteo. Este método ha sido defendido en distintos contextos análogos. Ver Gerald R. Winslow, Triage and Justice (Berkeley: University of California Press, 1982).
} 
Este razonamiento nos acerca bastante al tipo de caso que le preocupa a Rosenkrantz. En un país anómico e injusto como Argentina, dice Rosenkrantz, la aplicación generalizada y sistemática del derecho es necesaria para preservar la vía del cambio sistémico y el progreso social que éste permite. Incluso se podría plantear que, en casos extremos, de ello depende la supervivencia de la comunidad misma. Por eso, para Rosenkrantz, tenemos que evitar socavar la autoridad del derecho.

El éxito de este argumento dependerá, como Rosenkrantz reconoce, de cuestiones empíricas de difícil dilucidación. Dejemos de lado, no obstante, tales dificultades. Lo que me interesa destacar es que el tipo de consideración que Rosenkrantz nos ofrece en apoyo de la autoridad del derecho no concierne un deber de los individuos sino un deber del estado, en el sentido explicado arriba. El argumento del cambio sistémico, en efecto, no tiene sentido si lo analizamos desde el punto de vista del deber individual de obedecer el derecho. La preservación de la vida en comunidad o su desarrollo y progreso a través de la aplicación del derecho es un deber que compete al estado por sus particulares funciones. El individuo no tiene un deber análogo; cualquier deber que tenga al respecto será débil y no logrará imponerse, en general, a consideraciones auto-interesadas.

Por ello, para que la razón que Rosenkrantz nos ofrece tenga el peso justificatorio que él le asigna, ella debe situarse al nivel de la institución cuya función es proteger a la comunidad y promover su desarrollo y bienestar. Esta función, y en consecuencia los deberes que de ella se derivan, no alcanzan a los individuos que forman la comunidad. Para ellos, el cambio sistémico puede sin duda resultar importante, pero no cumplirá, insisto, el rol justificatorio que Rosenkrantz precisa. Los deberes del individuo, como los de los náufragos de nuestro ejemplo, no llegan tan lejos.

Como vimos, un rasgo central del concepto de derecho es que éste en general toma como punto de referencia los efectos que una conducta tiene en la jurisdicción del estado, y no el status del agente dentro de la comunidad. Un análisis centrado en los deberes del estado no tiene dificultad para justificar 
tal punto de contacto, ya que para poder proteger los intereses de la comunidad, el estado debe estar en condiciones de regular los actos que la afectan más directamente, independientemente de que ellos sean realizados por ciudadanos, residentes, turistas, o meros habitantes del mundo. Obviamente, esto, como dije antes, es sólo un principio general, y no debe faltar en él espacio para salvedades varias. Más aún, esta es una justificación del punto de contacto relevante entre sujeto y norma que el derecho establece, no una justificación del particular modo en que cada conducta es regulada. En otras palabras, esto es sólo un primer paso, pero muchos otros deben seguirlo antes de llegar a la justificación de una norma jurídica en particular. No obstante, como todo primer paso, es siempre preferible que se lo dé en la dirección correcta; de ello dependerá la pertinencia de los argumentos justificatorios subsiguientes que se ofrezcan.

3. El deber de imponer normas que profundizan la injusticia económica

Según vimos, el tipo de justificación que Rosenkrantz nos ofrece corresponde al deber del estado de imponer el derecho, no al del individuo de obedecerlo. Esto, como veremos, tiene particulares implicancias. Para empezar, es necesario esclarecer el alcance de la pregunta que Rosenkrantz busca responder, esto es, si se justifica aplicar el derecho aun en circunstancias de injusticia económica. Esta pregunta puede resultar, a primera vista, algo desconcertante. Si, como sugiere Rosenkrantz hacia el final, el derecho es la mejor manera de combatir la injusticia económica, ¿cómo podría la existencia de tal injusticia deslegitimar la aplicación del derecho? Al fin y al cabo, a nadie se le ocurriría que la existencia de enfermedades podría privar de justificación a la medicina, sino, más bien, todo lo contrario.

Obviamente, uno y otro caso difieren. Una cosa es que el derecho, al posibilitar el cambio sistémico, sea necesario para combatir la injusticia socioeconómica, y otra cosa es que de hecho lo haga. Rosenkrantz nos plantea 
una mera potencialidad. Podría ocurrir que, de hecho, un derecho en particular profundizara la injusticia socioeconómica. En tal caso, el argumento del cambio sistémico no funcionaría: que el derecho en general pueda servir para combatir la injusticia socioeconómica no sería justificación para aplicar un derecho en particular que la profundiza.

Podemos descartar la justificación de Rosenkrantz, entonces, en los casos en los que el derecho en cuestión sea en sí mismo un instrumento de la injusticia socioeconómica. Pero cabe preguntarse qué ocurre cuando el derecho tiene algunas normas que profundizan tal injusticia, otras que la combaten, y otras que no la afectan. Este caso es más complejo y, también, más probable. En él me concentraré en el análisis que sigue. Llamaré a las primeras normas "negativas", a las segundas "positivas" y a las terceras "neutras". Entenderé a las normas negativas en forma bastante amplia, de forma tal que incluyan, por ejemplo, el establecimiento de impuestos regresivos.

Si bien la aplicación de las normas negativas no puede defenderse, en principio, apelando a la necesidad de combatir la injusticia socioeconómica, puede ocurrir que dejar de aplicar las normas negativas impida aplicar las positivas y las neutras. Ello sería así si dejar de aplicar las normas negativas tendiera a fomentar un clima de anomia tal que en definitiva socavara la autoridad del derecho todo. Creo que este es, precisamente, el escenario que Rosenkrantz tiene en mente. La idea sería la siguiente: el derecho debe aplicarse en su totalidad, incluyendo las normas negativas, porque de lo contrario su autoridad se socavaría al punto de que sería imposible aplicar las normas neutras y las positivas. Si ello ocurriera, resultaría inviable el cambio sistémico y el progreso social que éste implica; incluso, tal vez, la preservación de la comunidad estaría en juego. El estado tiene el deber de evitar este mal mayor. Por ende, tiene el deber de aplicar el derecho en general, incluyendo las normas negativas. Este argumento presupone que aplicar normas negativas es un precio que debemos pagar para lograr la supervivencia del derecho.

Así planteadas las cosas, y situándonos en el plano de los deberes del estado, podemos reformular la pregunta que preocupa a Rosenkrantz -si existe 
un deber de obedecer el derecho en circunstancias de injusticia económicade la siguiente manera: ¿se puede justificar que el estado aplique normas negativas? El argumento de la supervivencia del derecho sería la respuesta de Rosenkrantz a esta pregunta. Este argumento, no obstante, nos enfrenta a dos problemas, uno coyuntural y otro estructural.

El primer problema deriva de que en muchos países existen normas constitucionales específicas que se refieren a la injusticia socioeconómica. Argentina, concretamente, ha incorporado en su constitución pactos internacionales de Derechos Humanos ricos en derechos socioeconómicos. ${ }^{13}$ Las normas constitucionales, dada su vaguedad, tienden a ser interpretadas a la luz de los valores morales imperantes. Este proceso lleva a que tales valores pasen a formar parte, en alguna medida, del criterio de validez de las normas jurídicas infraconstitucionales. La existencia de derechos socioeconómicos con rango constitucional, en consecuencia, implica que las consideraciones morales referidas a la justicia distributiva tomen la forma de consideraciones jurídicas y sean invocadas en calidad de tales para dejar de lado normas inferiores que se les opongan, como por ejemplo las normas negativas. En tal caso, tales normas serían rechazadas en términos jurídicos y no solamente morales. Por eso, si el estado opta por no aplicar una norma negativa por considerarla inconstitucional (esto es, contraria a los derechos socioeconómicos en cuya interpretación se incluyen consideraciones acerca de la justicia distributiva), tal decisión no implicaría dejar de lado el derecho sino, de hecho, aplicarlo. No importa aquí si es una buena o mala idea que el estado actúe de esta manera; el punto es que, si lo hace, difícilmente pueda alegarse que ello socava la autoridad del derecho, ya que no aplicar una norma negativa, en tal supuesto, sería la consecuencia de aplicar otra norma jurídica superior, no de ignorar el derecho. En ese contexto, parece poco probable que dejar de

\footnotetext{
${ }^{13}$ En especial, pero no solamente, el Pacto Internacional de Derechos Económicos, Sociales y Culturales.
} 
aplicar una norma negativa tenga el efecto que el argumento de la supervivencia del derecho presupone.

Pero incluso si dejamos esto de lado, existe un segundo problema. Este problema ya no depende de la coyuntural constitucionalización o legalización de derechos socioeconómicos, sino que, como anticipé, es más estructural. Para desarrollar mi argumento, apelaré, una vez más, a un caso hipotético. Supongamos que existe un gobierno que en general garantiza la protección física de la población, provee beneficios sociales como educación gratuita, salud pública y asistencia a los carenciados, y maneja los instrumentos de política económica con eficiencia y honestidad. Sin embargo, este gobierno con alguna regularidad viola los derechos de sus súbditos en materias tales como libertad de expresión y de asociación; en ocasiones, incluso llega a apremiar a algún opositor político. La población en general desaprueba estos hechos, pero ello no obstante reconoce que es mejor tener este gobierno que no tener ningún gobierno, o incluso que es mejor este gobierno que las alternativas que se pueden vislumbrar en ese país. Los ciudadanos, en definitiva, creen que este gobierno está, en general, justificado. Sin embargo, esto no quiere decir que esta justificación general sea algo que el propio gobierno pueda invocar para defenderse cuando se lo acusa de violar derechos individuales. El gobierno en cuestión no podría alegar que sus varias virtudes, reconocidas por la población en las urnas, justifican instancias de violaciones a los derechos individuales.

Pensemos sino en este otro ejemplo más pedestre. Supongamos que en una empresa trabaja un empleado que, aunque presta su tarea con ponderable diligencia, ocasionalmente se queda con algún vuelto de la caja chica. El empleador está al tanto de ello, pero decide mantener al eficiente aunque deshonesto empleado en su puesto porque concluye que los beneficios que trae a la empresa su servicio superan los costos de sus deslices. El empleador diría que tener a este empleado está justificado. Pero, nuevamente, esto no quiere decir que el empleado pueda invocar los beneficios que trae a la empresa para justificar sus actos deshonestos. Esta justificación no está disponible 
para el empleado, y sería absurdo que la utilizara en su defensa si el empleador alguna vez lo confrontara.

Un dato fundamental en estos casos es que tanto la violación de derechos individuales por el gobierno como la realización de actos deshonestos por el empleado son eventos que uno y otro controlan, en el sentido de que está en su poder que esos actos cesen. Más aún, la interrupción de los actos reprochables no traería naturalmente aparejada la interrupción de los beneficios que gobierno y empleado proveen; esto sólo ocurriría si ellos así lo decidieran. ${ }^{14}$ Por eso, no podríamos considerar que estos actos están justificados, aunque sí pueda estarlo, desde el punto de vista del ciudadano y del empleador, votar al gobierno y mantener al empleado en su puesto, respectivamente.

Con esto en mente, volvamos al caso que nos ocupa. Incluso si el argumento de la supervivencia del derecho proveyera una justificación general para aplicar el derecho en su totalidad, incluyendo las normas negativas, este tipo de justificación no estará disponible para el estado. Dado que el estado es un artífice en la creación del derecho, no puede tratar a éste como algo caído del cielo que no le queda más remedio que aplicar: el estado tiene la posibilidad de derogar las normas negativas y reemplazarlas por otras positivas o neutras. La vigencia de las normas negativas, en definitiva, es algo que el estado puede controlar, y ello priva de poder justificatorio al argumento de la supervivencia del derecho.

El argumento de la supervivencia del derecho no puede, a mi juicio, sortear los dos problemas señalados. Esto no quiere decir que la aplicación de normas negativas, esto es, normas que profundizan la injusticia económica, nunca esté justificada. Aquí analicé sólo una clase de justificación -aquella

\footnotetext{
${ }^{14}$ En este sentido, este razonamiento es similar al que ofrece G. A. Cohen en relación con el principio de diferencia de Rawls en "Incentives, Inequality and Community", en Stephen Darwall, ed., Equal Freedom (The University of Michigan Press, 1995) p. 331-397.
} 
que, según entiendo, se deriva del argumento presentado por Rosenkrantzpero obviamente existen otras. Al fin y al cabo, la justicia distributiva no es la única justicia que el estado debe procurar. ${ }^{15}$ Puede ser, por ejemplo, que razones de justicia retributiva o correctiva justifiquen en ciertos casos la aplicación de normas negativas. O puede ser que razones internas a la justicia distributiva recomienden aplicar normas negativas en algún caso, por ejemplo, por consideraciones como las que animan el principio de diferencia de Rawls. Pero esta línea argumental nos llevaría por un camino muy distinto del que Rosenkrantz transita, y no pretendo siquiera asomarme a él. En todo caso, cabe señalar que concebir la justificación de la aplicación del derecho desde la perspectiva de los deberes del estado cierra algunas puertas pero, también, abre otras.

\section{Conclusión}

$\mathrm{Si}$, como dije, la batalla relevante para dilucidar la cuestión que ocupa a Rosenkrantz debe librarse en el plano justificatorio, ¿por qué él elige encararla desde la perspectiva conceptual? Creo que la respuesta, como sugerí en algún momento, se vincula con la preocupación subyacente que lleva a Rosenkrantz a emprender este proyecto. Situado en Argentina, y alarmado, como toda persona sensata, por la rampante anomia que nos afecta, Rosenkrantz considera fundamental que se fortalezca el imperio del derecho, no sólo como consecuencia de su aplicación o ejecución (lo que en inglés se conoce como enforcement), sino también a partir de la convicción de sus súbditos de que eso es lo que se debe hacer. El problema está en cómo entendemos ese "debe". Si lo entendemos como la existencia de un deber jurídico, estaríamos diciendo, simplemente, que el derecho debe obedecerse

${ }^{15}$ El argumento clásico al respecto se encuentra en Aristóteles, Ética para Nicómaco, Libro V. 
cuando el derecho dice que debe obedecerse. Este análisis, claro está, resultaría circular. La otra forma de entender el deber de obedecer el derecho es desde el punto de vista de un sistema normativo externo a él, típicamente la moral. Rosenkrantz es reacio a tomar esta segunda ruta. Él teme que, dado que la moral ha sido siempre materia de controversia (y, nos dice, hoy lo es más que nunca), si supeditáramos el deber de obedecer el derecho a consideraciones morales no lograríamos el afianzamiento del derecho que un país como Argentina requiere. Este temor lleva a Rosenkrantz a la búsqueda de una tercera vía; pero mi impresión es que los contornos de esa vía aún no se encuentran claramente definidos, y de allí que cierta oscilación entre distintos planos de análisis tienda a permear su trabajo.

En particular, creo que Rosenkrantz por momentos pretende brindar una justificación de la práctica de aplicar el derecho a partir de consideraciones conceptuales. Esto es, como vimos, lo que ocurre en la primera parte de su trabajo, dedicada a desestimar teorías alternativas. ${ }^{16}$ Así, por ejemplo, cuando nos dice que las teorías del consentimiento no logran explicar por qué debemos obedecer el derecho aun cuando no lo consentimos, parece estar diciendo que el derecho de hecho se aplica aun cuando no lo consentimos (lo que resulta fácticamente indiscutible), no que el derecho debe aplicarse aun cuando no lo consentimos. Sin embargo, si esto es lo que Rosenkrantz quiere decir, como vimos, su propia teoría tampoco logra explicar cada instancia de aplicación del derecho positivo, ya que éste sin duda alcanza a quienes no son miembros. Rosenkrantz podría aquí cambiar el plano de análisis y afirmar que el derecho no debería aplicarse a quienes no son miembros, pero en ese caso cabría cuestionar que no se haya movido en el mismo plano para analizar

\footnotetext{
${ }^{16}$ Dworkin, en cambio, adopta un punto de vista moral para criticar las teorías sobre la autoridad del derecho basadas en el consentimiento, en el fair play y en el deber de justicia. Ver Law's Empire (Cambridge, Massachusetts: The Belknap Press of Harvard University Press, 1986) p. 192-5.
} 
las teorías rivales: su crítica a éstas pretendía ser conceptual, no valorativa. Como también vimos, Rosenkrantz podría sortear algunos de estos escollos situando la discusión en torno al concepto de derecho, pero este no es un camino que él tome explícitamente ni que aparezca particularmente promisorio.

La dificultad de ubicar esta tercera vía aflora también en el breve análisis que Rosenkrantz hace de la desobediencia. Al introducir este tema, afirma Rosenkrantz que la legítima defensa y el estado de necesidad son supuestos en los que "la desobediencia, sin duda, está justificada", y asegura que estos son casos fáciles. El problema es que son fáciles porque no son realmente casos de desobediencia. La noción relevante de desobediencia es la desobediencia al derecho, no la desobediencia a algunas normas del derecho que está permitida por otras normas del derecho. Un ejemplo de libro de texto de "justificación" es el caso del bombero que rompe un vidrio, violando así la norma jurídica que prohíbe hacerlo, para rescatar a una persona de las llamas. Nadie diría que el bombero está desobedeciendo el derecho. Lo mismo se aplica a otras causas de justificación, como la legítima defensa. Si yo golpeo a una persona para evitar que me mate, no estoy desobedeciendo el derecho en ningún sentido relevante. No se trata, como dice Rosenkrantz, de un caso en que "la desobediencia, sin duda, está justificada" sino de un caso en que la conducta está justificada por el derecho y, por ende, no constituye una instancia de desobediencia. En este caso, nuevamente, Rosenkrantz oscila entre las consideraciones legales y las morales, y por momentos no queda claro de qué tipo de justificación está hablando.

Como este comentario sugiere, tiendo a ser escéptico acerca de la posibilidad de encontrar un lugar adecuado para la tercera vía que Rosenkrantz está explorando. Creo que Rosenkrantz no debería ser tan reacio a ubicar su análisis en el plano de la justificación moral, en especial si tenemos en cuenta que, según sostuve, debemos analizar la justificación de la autoridad del derecho en función no del deber individual de obedecerlo sino del deber estatal de imponerlo. Este deber resulta más permeable al tipo de consideraciones que mueven a Rosenkrantz, en particular aquellas que se 
vinculan con el interés (más aún, la necesidad) de la comunidad de cambiar sistémicamente y lograr así su progreso. No creo que esta línea de justificación, una vez ubicada en su justo lugar, carezca de importancia. 